\title{
International Partnership Helping to Bring Appropriate Biofuel Technology to Rural Cameroon
}

\author{
Jeffrey R. Seay, PhD, PE \\ Assistant Professor \\ Chemical and Materials Engineering \\ University of Kentucky \\ jseay@engr.uky.edu
}

\author{
Isaac F. Zama, PhD \\ US Representative \\ African Center for Renewable Energy and \\ Sustainable Technology \\ ifzama@gmail.com
}

\author{
Bradley D. Butler \\ Graduate Student \\ Mechanical Engineering \\ University of Kentucky \\ bdbut13@engr.uky.edu
}

\begin{abstract}
In May 2012, a group of chemical and mechanical engineering students from the newly established University of Kentucky Appropriate Technology and Sustainability (UKATS) undergraduate research group embarked on a 10 day visit to Bangang Village, Cameroon in West Africa. The goal was to implement a multidisciplinary engineering service-based project to develop appropriate, sustainable biodiesel and biochar technology for use by local villagers. The participating students had worked on this design project as part of their capstone design course in both Chemical and Mechanical Engineering as well as part of a special elective course that included an embedded study abroad component. Poverty and rapid population growth have led to the accelerated destruction of natural resources throughout the developing world, particularly West Africa. The purpose of this project was not only to introduce students to the concepts of sustainability, service based learning and appropriate technology, but to get them beyond the textbooks and laboratories and solve real problems that impact real people around the world.
\end{abstract}

Index Terms: Appropriate technology, biochar, biodiesel, sustainability

\section{INTRODUCTION}

Engineering students often find themselves with a very myopic view of the world. The intense workload required of undergraduates often limits their focus to the next assignment due date or upcoming exam. However, it is important for engineers especially to be aware that they are part of a global community and that the processes and products they design can have far reaching impacts. For this reason, it is important to include projects with real world outcomes. This paper describes a design project which emphasized sustainability and appropriate technology undertaken by a group of chemical and mechanical engineering students participating in the University of Kentucky Appropriate Technology and Sustainability (UKATS) undergraduate research group at the University of Kentucky - Paducah Extended Campus. This service based 
design project was conducted in collaboration with a non-governmental organization (NGO) called the African Center for Renewable Energy and Sustainable Technology (ACREST) and focused on the development of low-cost processes for generating biodiesel and biochar from locally available construction materials and feedstocks in Cameroon in West Africa. This project and trip to Cameroon was the culmination of a yearlong outreach and service-based learning effort that included an embedded study abroad component. The effort was organized as an undergraduate research project that included students from Chemical and Mechanical engineering in their sophomore through junior years.

\section{Project Objectives}

There is a need for service learning projects to develop affordable technology to allow villagers in rural Cameroon, or other underdeveloped tropical regions, to generate their own sustainable source of fuel from locally available materials and feed stocks. Petroleum based liquid fuels for transportation, or operating power generators, are often dirty and expensive and supplies in rural or remote regions can be unreliable. Additionally, solid fuels like charcoal, which are the primary source of cooking fuel in rural Cameroon, are produced by inefficient methods which can lead to both a lower quality product as well as accelerated deforestation. Finally, the charred material used to produce charcoal briquettes can also be used as a soil amendment, commonly called biochar. Biochar and charcoal can both be produced by the same process. Therefore the objective of this service learning project was to develop a simple, safe, efficient, and low-cost integrated process for producing charcoal/biochar and biodiesel constructed from recovered or recycled materials and utilizing locally available feedstocks. The process was intended to be used by individuals or small groups to generate fuels for personal or local consumption. Based on this requirement, the processor was designed to produce 5 gallon batches of biochar or biodiesel at a time. However, the technology was easily scalable for larger batches. The prototype processor was to be operated by ACREST, who would then teach the local villagers how to construct and operate their own processors. Based on recommendations from ACREST, the cost for producing the processor was kept below 100 USD.

\section{Project Background}

\section{Linking Engineering Students with the Developing World}

ACREST was founded in 2003 and officially registered with the Government of Cameroon as an NGO in 2005. (See Figures 1 and 2). The goal of ACREST is to promote renewable energy along with appropriate and sustainable technologies as tools to combat poverty and deforestation. To achieve its goals, ACREST develops the capacity of its technicians, who for the most part are primary school dropouts but are incredibly talented, to design and build appropriate technologies in Cameroon rather than importing them. ACREST is privately funded by remittances from its members who live and work abroad. As such, its resources are very limited. To overcome this limitation, ACREST partners with engineering departments at US universities to undertake collaborative and service based learning projects in which US students use the resources of their universities to develop projects throughout the year and then spend their summer implementing the projects alongside ACREST technicians. 


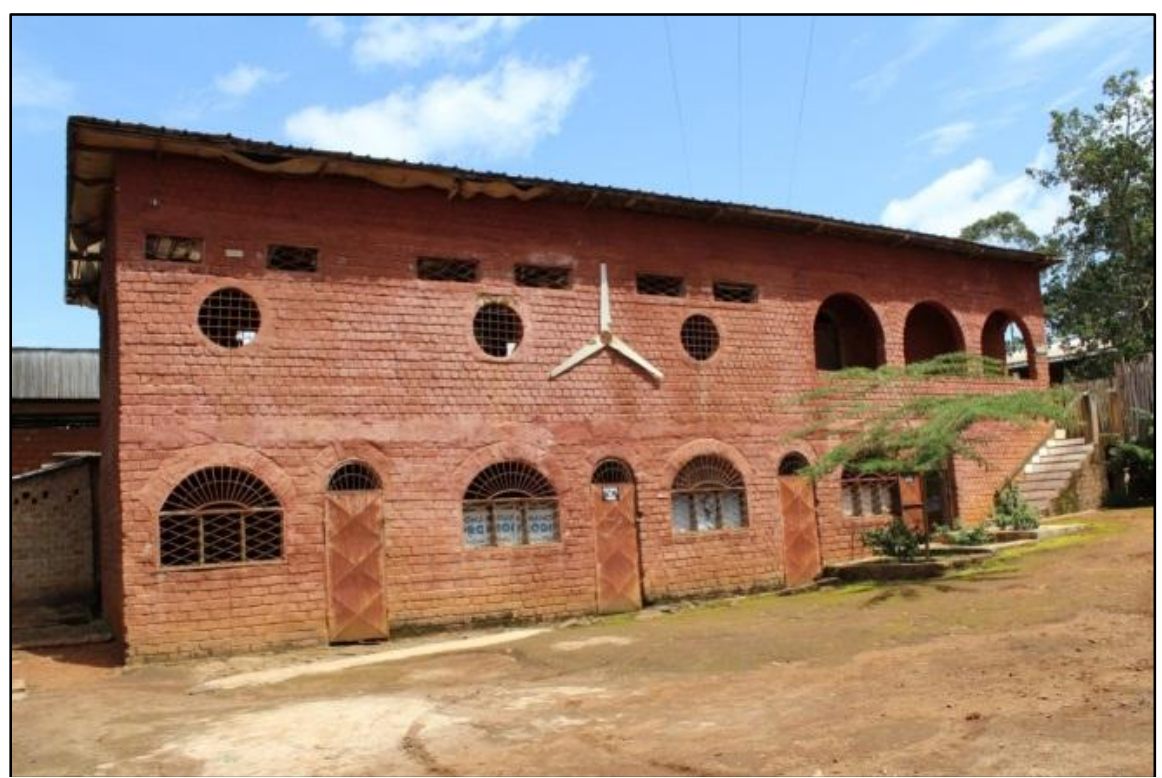

FIGURE 1

ACREST WORKSHOP AND TRAINING FACILITY IN BANGANG VILLAGE, CAMEROON

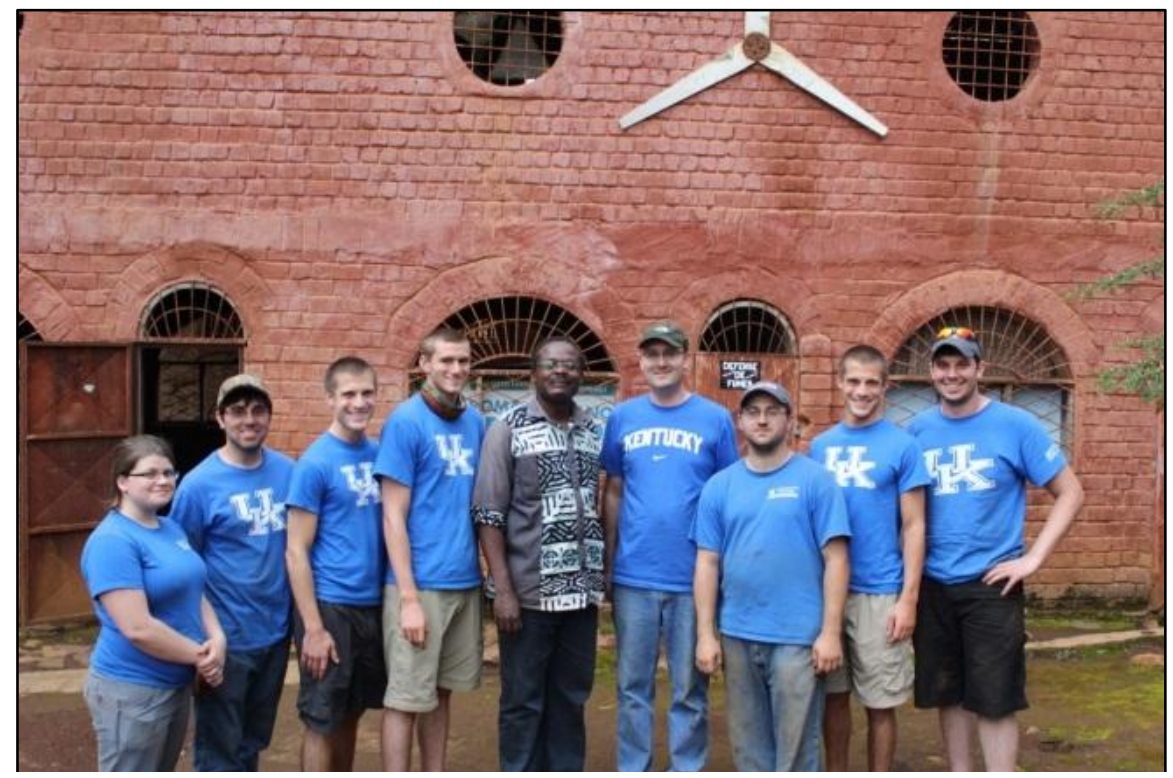

FIGURE 2

UKATS RESEARCH GROUP MEMBERS WITH ACREST FOUNDER DR. VINCENT KITIO

Since 2008, ACREST has partnered with the Massachusetts Institute of Technology for the development of a handheld corn sheller and an irrigation pump ${ }^{1}$; with Purdue University for the development of a Basic Utility Vehicle production center and a micro-hydro electricity generator ${ }^{2}$; and most recently with the University of Kentucky - Paducah Extended Campus chemical and mechanical engineering departments for the development of a sustainable biodiesel and biochar/charcoal production technology. ACREST is open to partnering with Universities 
across the world interested in having their students design and implement appropriate technologies in and for a real and developing world context.

The University of Kentucky - Paducah Extended Campus first became involved with ACREST at the 2011 National Sustainable Design Expo in Washington, DC, sponsored by the US Environmental Protection Agency, where a student group was participating in the People, Prosperity and the Planet Student Design Competition for Sustainability and presenting the results of a biodiesel research project ${ }^{3}$. It was through this project that the collaboration between the University of Kentucky - Paducah Extended Campus and ACREST was established.

ACREST was involved with other student teams participating in the National Sustainable Design Expo. There the authors learned about the other projects that ACREST has undertaken over the years and first discussed the possibility of designing a low-cost biodiesel process, suitable for operating in the tropics. The team immediately decided to take up the challenge.

\section{Designing Appropriate Technology for Underserved Communities}

One of the key design challenges of this student service and engagement based learning project was to ensure that the technology developed was appropriate for the community for which it is intended. In other words, the student team had to take the time to understand the needs as well as the capabilities of the local villagers. This meant that the designs must not only be low-cost, but also simple, safe and easy to explain to a population with limited formal education. Furthermore, the team had to work with the materials and feedstocks locally available to the villagers. To achieve this goal, the student team had to decompose the design problem to its fundamental elements: heating, cooling, mixing, product recovery and purification. With some experience, the students found that simply trying to reproduce the technology used in industrialized countries for conditions in the tropics was a mistake. A better approach was to completely rethink the process from scratch - to consider what was actually required, and figure out how to achieve that with the resources available. Once this approach was taken, truly innovative solutions could be developed, as described below.

\section{Sustainable Engineering and Design}

Ensuring that the natural resources required to produce the energy and fuels needed by society are utilized in a way that ensures their availability for future generations is the core of the field of sustainability. In its 1987 report titled Our Common Future, the U.N. World Commission on Environment and Development, also commonly called the Bruntland Commission, defined sustainable development as follows:

"Sustainable development is development that meets the needs of the present without compromising the ability of future generations to meet their own needs." 4

Although there is no single accepted definition of the term sustainability, the Bruntland Commission definition of sustainable development forms the basis of what sustainability means to the field of engineering. For engineers in particular, sustainability has come to refer to the goal of designing, operating and maintaining products and processes in a manner that is economically viable, environmentally benign, and beneficial to society. In other words, a sustainable product or process is one that is designed, operated and maintained to meet the triple 
bottom line of economics, environment and society, both now and in the future. This is especially important in underdeveloped economies. Ensuring that technology is utilized in a way that is socially responsible as well as environmentally benign and economically viable is critical to a sustainable future. Resource conservation is especially sensitive in developing economies; therefore projects that are aligned with sustainable biofuels are especially important.

Furthermore, the National Academy of Engineers has expressed the need for sustainability in engineering education in its report titled The Engineer of 2020: Visions of Engineering in the New Century as follows:

"It is our aspiration that engineers will continue to be leaders in the movement toward the use of wise, informed, and economical sustainable development. This should begin in our educational institutions and be founded in the basic tenets of the engineering profession and its actions."

Design projects like the collaborative project with ACREST described here are a key part of fulfilling this need as espoused by the NAE. Having a partner in country is crucial to ensure that the project outcomes are truly aligned with the needs of the target population.

\section{Embedded Study Abroad Program}

This project was organized as a special elective utilizing the newly established embedded program model for study abroad at the University of Kentucky. The embedded study abroad program model differs significantly from the traditional study abroad program, where students typically spend a semester or a summer at a foreign university and complete traditional coursework for class credit. The embedded program model allows course instructors to embed a travel component into a traditional core course or elective. This model reduces both the expense and the time burden on the participating students. The students are able to participate and experience another culture without disrupting either the academic year, or potential summer internships, which are so important for engineering students. Despite the abbreviated travel component, study abroad programs of similar length have been shown to be quite effective by other researchers $^{6}$. For this biodiesel project, the travel component comprised 1 credit hour of the 3 hour special elective. The other 2 credit hours consisted of class meetings and lab time to work on the process designs and fabricating the process prototypes.

Along with this new study abroad model, the university has established a scholarship fund for students participating in embedded study abroad programs. Although the scholarships did not cover the entire cost of the program, it reduced the student cost significantly. Additional funding from the College of Engineering Dean's Office contributed additional funding to cover student expenses. In total, participating students were able to get up to $90 \%$ of the program costs covered.

\section{Study Abroad at an Extended Campus Program}

All the undergraduate students involved in this project are enrolled in the University Of Kentucky College Of Engineering Extended Campus Program in Paducah. The Paducah Extended Campus was established in order to provide educational opportunities in Chemical and Mechanical Engineering in the largely underserved region of Western Kentucky. According to 
data from the National Science Foundation, Kentucky ranks in the bottom quartile of states in Bachelor's degrees in natural sciences and engineering conferred per 1,000 individuals ${ }^{7}$. Furthermore, according to the Kentucky Council on Post-Secondary Education, the western-most region lags behind the rest of the state in percentage of adults with a bachelor's degree or higher $^{8}$. As a result, bringing opportunities to engage students in international projects is especially impactful. The opportunity to participate in projects that impact the lives of people around the world is important in the Western Kentucky region because students who are remote from the main campus often find it difficult to find this kind of opportunity during their college experience.

\section{Service Based Design Project Methods and Procedures}

\section{Background}

Engineers come in a wide variety of disciplines, but all share one common theme - we are at our core, problem solvers. The project undertaken by the group of chemical and mechanical engineering students introduced them to a completely different kind of problem solving. Normally, when considering a design project, engineers look to new technology and best available practices. However, when designing processes for developing economies, a better strategy is to turn to older, established technologies, which may be a better option due to the lack of modern infrastructure and manufacturing capacity. Therefore, the focus for this project was to instead apply pre-industrial technology and techniques in an innovative and potentially transformative way. Although in some cases this can mean sacrificing efficiency. For projects of this kind it may be a necessary tradeoff.

For example, the production of biodiesel from vegetable oil requires a simple alcohol like methanol and a basic catalyst to complete the reaction. Methanol is prohibitively expensive in Cameroon; however, in pre-industrial times methanol was recovered from wood during the process of making charcoal. Charcoal making by traditional methods is still widely practiced around the world, including Cameroon. One of the objectives of this project then is to develop techniques for collecting and recovering the methanol released during the traditional charcoal making process. In addition to methanol and vegetable oil, a basic catalyst is needed for making biodiesel - typically sodium hydroxide or potassium hydroxide. Again, in pre-industrial times these chemicals were extracted from wood ash for the purpose of soap making - a practice still widely applied in the developing world. By integrating methanol recovery and hydroxide extraction into the biodiesel manufacturing process, an innovative, low cost biodiesel processor can be constructed for use by villagers in Cameroon. To keep production costs low, locally available materials of construction such as used oil drums, junk yard car parts and plumbing supplies were utilized.

Additionally, many student projects at the undergraduate level are "textbook" problems designed to meet a certain set of educational objectives. In the case of this service based learning project, there were real people whose lives would be directly impacted by the results. The students knew that there was much more than a grade riding on the results they achieved. They had a real opportunity to use their engineering skills to improve people's lives, and that was very motivating to them. Finally, the students benefitted from the experience of working in multidisciplinary teams. The students from chemical and mechanical engineering were able to 
educate each other on the details and strengths of their individual disciplines. The students found that only by working together could they develop truly innovative solutions.

\section{Research Approach}

Although both destructive wood distillation for methanol recovery from charcoal manufacture and the production of biodiesel from vegetable oil are certainly well understood, there are numerous technical challenges involved with adapting this technology for the developing world. Principle among these challenges are: ensuring that the design is robust enough to handle wide variations in feedstock quality; developing quality control safeguards for production in rural areas; and ensuring that the chemistry is well understood based on locally available resources. Additionally, numerous techniques for producing biodiesel from vegetable oil on a small scale have previously been developed. Perhaps the most well know process is the Appleseed processor ${ }^{9}$. This open source design is based on converting a home hot water heater into a batch reactor for producing biodiesel. Unfortunately, even this simplified design is too complex for use in many developing regions. Therefore the research approach will be to determine the simplest approach to producing biodiesel and biochar without utilizing electricity, moving parts or sophisticated controls, even if that approach required sacrificing efficiency.

\section{Biodiesel Process}

Biodiesel is a liquid fuel produced by the transesterification reaction of vegetable oils or animal fats and an alcohol such as methanol or ethanol to biodiesel (known chemically as fatty acid methyl ester, or FAME) in the presence of a basic catalyst, such as sodium or potassium hydroxide. Glycerol is produced as a side product of this reaction and must be decanted from the final product. In Cameroon, calcium oxide rocks, commonly called slaked lime, is readily available at local markets at low cost. Dissolving this calcium oxide lime in water generates calcium hydroxide. Although inferior to sodium or potassium hydroxide, calcium hydroxide can be used to catalyze the transesterification reaction. Additionally, the production of lye from wood ash for traditional cooking methods is widely practiced. The tropics are rich in plant oils such as palm oil, jatropha oil and castor oil. Thus, two of the three raw materials, oil and a base catalyst, for the production of biodiesel are widely available. A photo of the biodiesel processor constructed by the student team is shown in Figure 3.

The primary design challenge the student team faced was the requirement to design a processor that needed no electricity or moving parts. Typically, in an industrial process, the biodiesel is produced in a well-mixed batch reactor operating at $55-60^{\circ} \mathrm{C}$. The reaction that produces FAME from vegetable oil is mass transfer limited, meaning that good contact between the alcohol and oil phases is necessary for the reaction to proceed. Heating the reactor contents speeds up the reaction rate, but the temperature is typically maintained below the boiling point of the alcohol in order to prevent evaporative losses. The mixing and precise control used in industrial processes was not practical in rural Cameroon, especially given the requirement to maintain affordability for the typical villager. The students overcame this design challenge with a novel design. The student reactor used a double boiler design to maintain a temperature of $100^{\circ} \mathrm{C}$ without needing electronic controls. Because $100^{\circ} \mathrm{C}$ is above the normal operating temperature for biodiesel production, the team utilized a knockback reflux condenser made from 
a junkyard car radiator to eliminate the losses of the alcohol feedstock. This novel design proved to not only be functional, but also maintained the low-cost requirement.

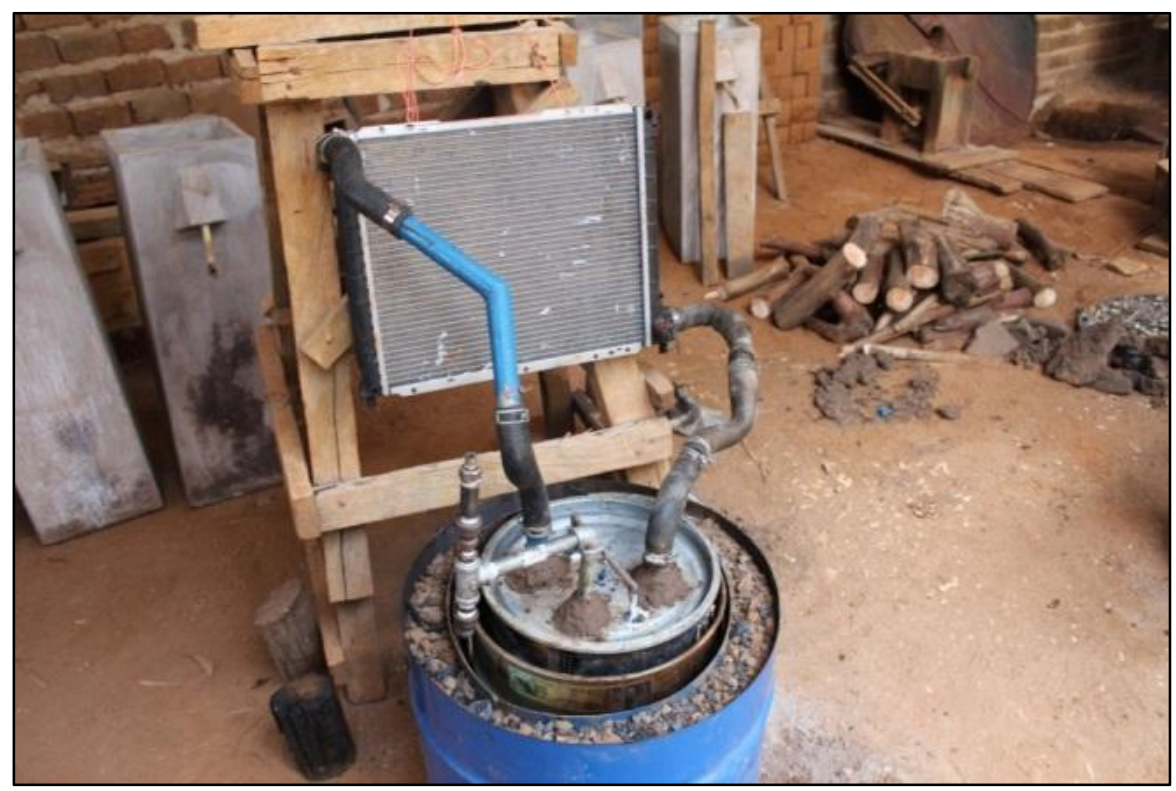

FIGURE 3

LOW COST BIODIESEL PROCESSOR BUILT AT ACREST FACILITY IN BANGANG, CAMEROON

\section{Biochar Process}

Charcoal is the primary cooking fuel used in the developing world, including Cameroon. Therefore, it was logical to integrate the production of charcoal with the production of biodiesel. Biochar is similar to charcoal, but instead of being pressed into briquettes it is ground up and used as a soil amendment to improve water and nutrient retention in poor soils ${ }^{10}$. Biochar is typically produced in a heated kiln via a process called pyrolysis, or heating in the absence of oxygen. If the gases released from the wood during the pyrolysis process could be condensed and collected, the methanol it contains could be recovered in a batch still and used in the biodiesel process. The remaining "wood vinegar" as it is called can be utilized as a nonsynthetic pesticide ${ }^{11}$. Therefore, three products - charcoal, methanol and pesticide - can all be collected from the same simple, low cost process. A photo of the biochar processor is illustrated in Figure 4.

The primary design challenge with designing a low cost biochar kiln is eliminating heat losses to the atmosphere. The student team addressed this problem by designing a double walled kiln with the annular space filled with ashes and clay to serve as insulating materials. See Figures 4 and 5. The process is fueled by a wood fire in the bottom of the kiln. The increased efficiency of the insulated design greatly improves the sustainability of the process. 


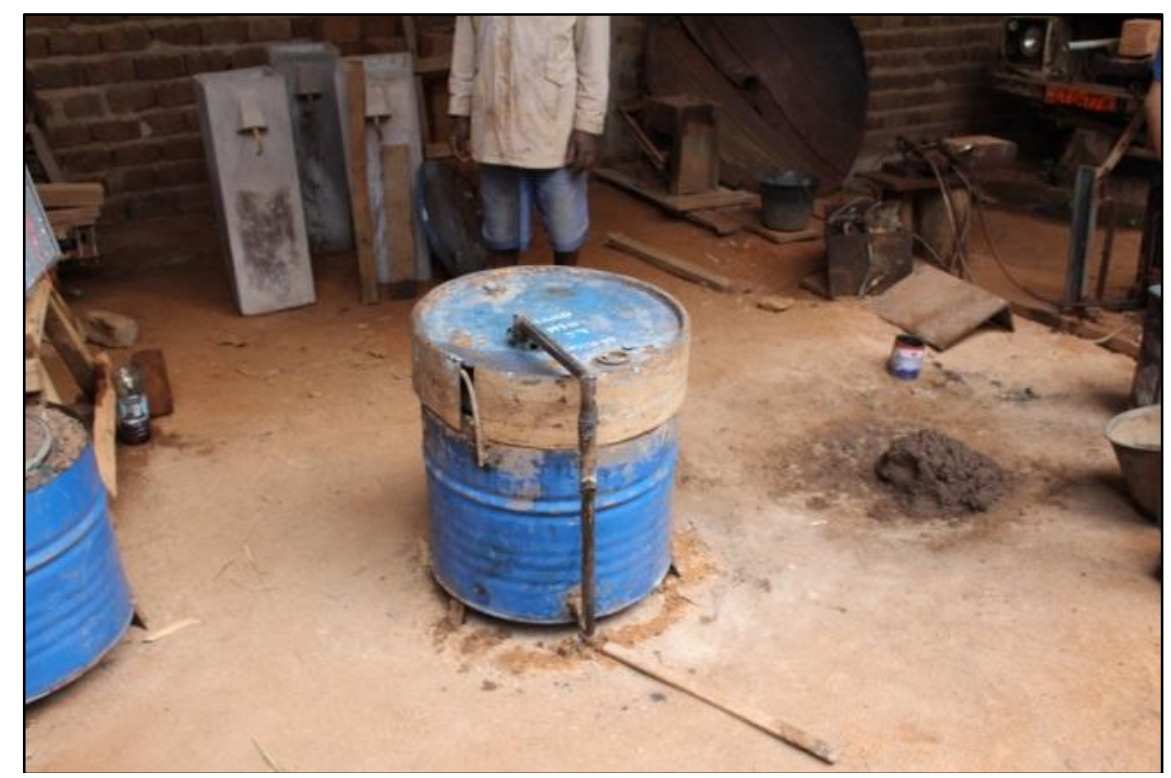

FIGURE 4

BIOCHAR KILN PROTOTYPE BUILT AT ACREST FACILITY IN BANGANG, CAMEROON

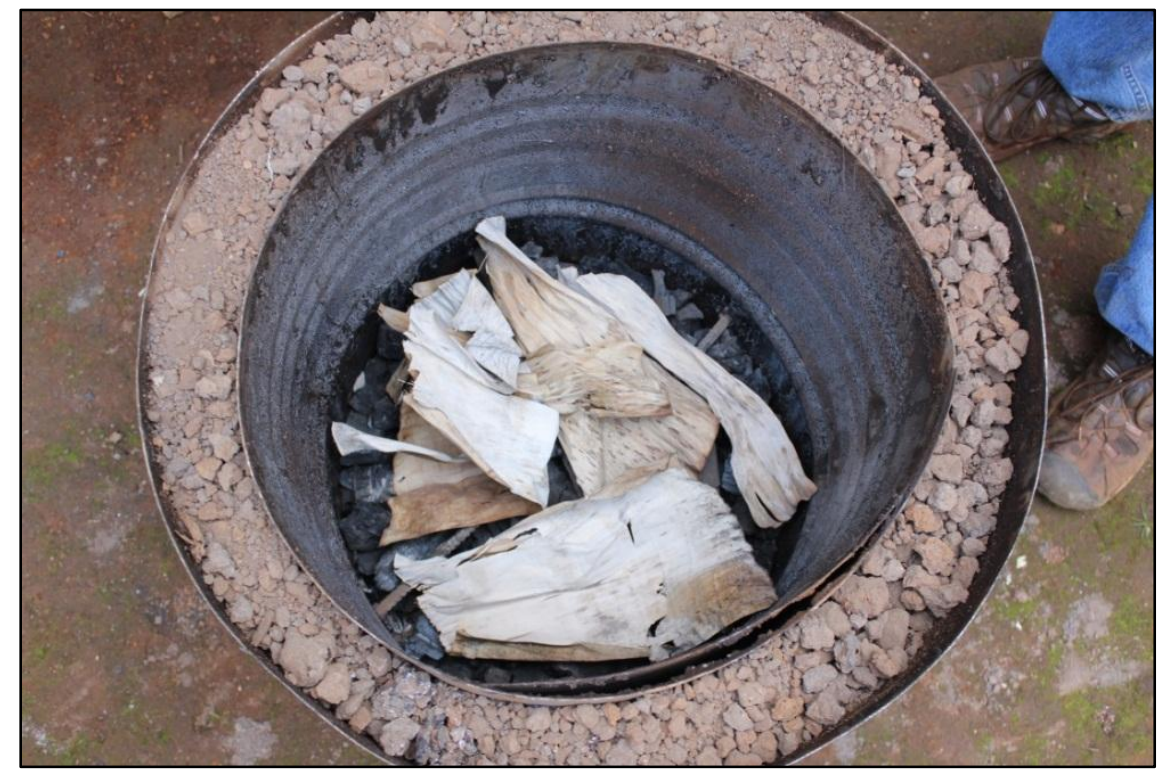

FIGURE 5

DOUBLE WALLED, INSULATED HEATING UNIT READY FOR FIRE

\section{Integrated Design}

In order to simplify the fabrication process, both the biodiesel and biochar processors use a common heating unit. The double walled unit used to heat the biochar kiln is the same unit used to provide energy to the biodiesel reactor. The unit can also be used to heat a batch still to purify the methanol recovered from the condensed wood gasses released during biochar pyrolysis. 
Additionally, the radiator used as the reflux condenser during the production of biodiesel is also used to condense the wood gases during pyrolysis. This integrated design was one of the principal innovations developed by the student design team.

This design project not only gave the participating students the chance to practice their engineering skills, it gave them an opportunity to engage with an underserved community. Cameroon is a very poor country with the average Cameroonian living on the equivalent of 2,300 USD per year, which ranks it $184^{\text {th }}$ in the world ${ }^{12}$. Being able to develop a process to improve the access and affordability of energy has an immediate positive impact on the lives of people. In addition to simply designing and constructing their biodiesel and biochar apparatus, the student team also produced instructional materials including videos to educate the potential users of the technology on how to operate it. The team also instructed the technicians working at the ACREST facility in Bangang Village how to produce the processors themselves so that they can continue to make more for distribution to people in the region. See Figure 6.

As previously described, the project was organized primarily as a special 3-hour elective course with an embedded travel component accounting for one of the three credit hours. To ease the time burden on the students, some elements of the project were integrated into the capstone design sequence in chemical and mechanical engineering. The students designed and built their prototypes during the academic year, but travel to the ACREST facility was included as part of the graded course requirements. In addition to their completed designs, the course also included a written component. In order to receive their final grade, the students were required to submit a journal detailing their experiences and impressions of their visit to Cameroon. Some of those impressions are included in this paper in the following section.

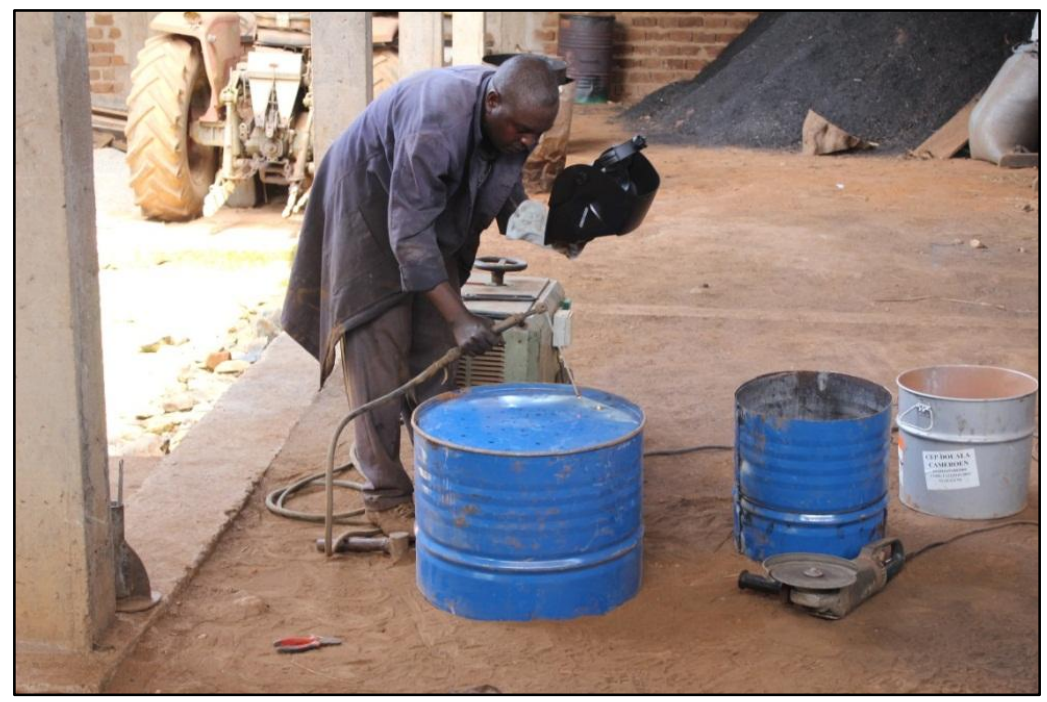

FIGURE 6

AN ACREST TECHNICIAN FABRICATES THE INTEGRATED WOOD FIRED HEATING UNIT 


\section{RESUlTS AND DISCUSSION}

\section{Project Results}

By the conclusion of the visit to Bangang Village, the student team had successfully built the prototype biodiesel and biochar processor and operated them successfully at the ACREST facility. The first batch of palm oil based biodiesel produced in the prototype processor was successfully tested in a diesel generator at ACREST. See Figure 7. Based on these results, the project was considered a success. However, despite the success, the team will continue to work on refining the process to increase efficiency and improve the product quality. The first batch of biochar was also successfully produced and methanol containing wood gas was collected. However, the quantity of biochar produced was approximately equal to the fuel used to make it. From an energy balance perspective, this is not acceptable. Moving forward, the primary goal of the team will be to improve the efficiency of both the biodiesel and biochar processes.

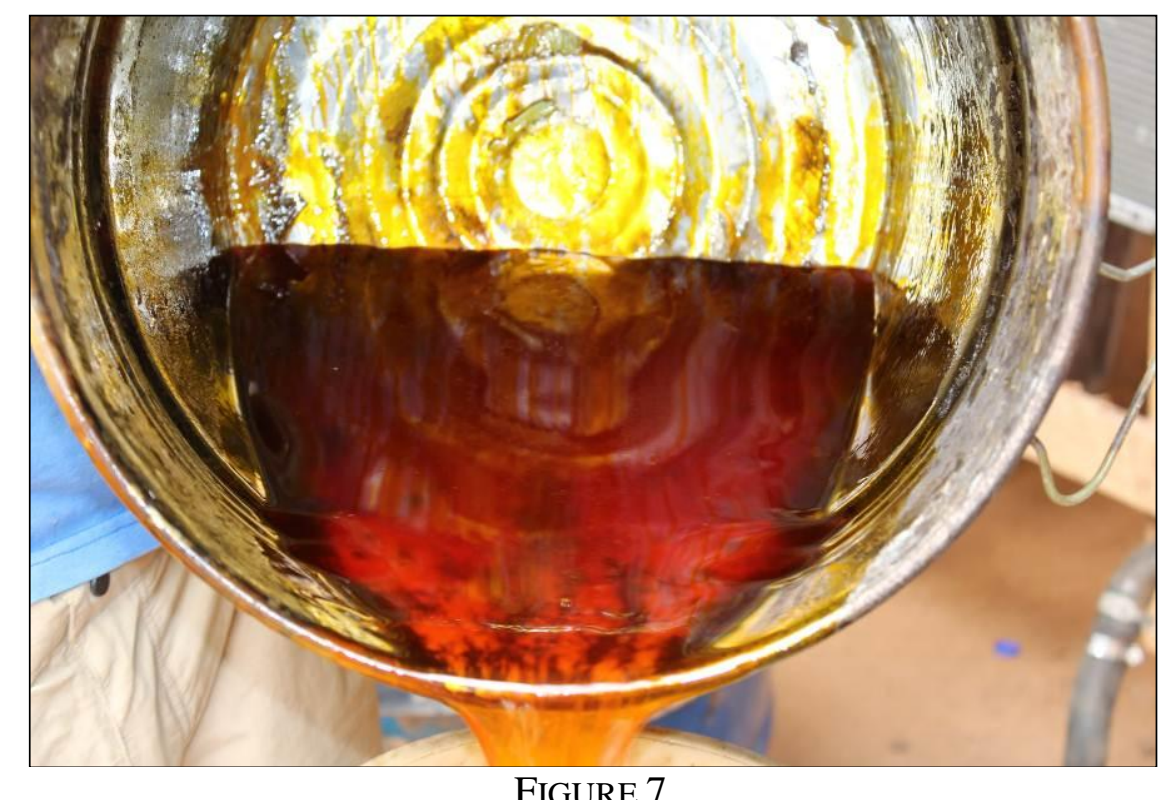

Crude Palm Oil Based biodiesel Produced at Bangang Village

\section{Student Experiences}

Although being involved in a service based design project of this kind was quite beneficial to the participating students, the travel component enabling the students to experience life in Cameroon first hand was what proved to be the most influential. Once the UKATS student team arrived in Cameroon, they were immersed in what seemed to be a completely different world from the one they were used to in the United States. Cameroon, being a developing country, provided many new experiences as well as design challenges. The lifestyles of people living in this developing country were very different from what the team was used to. ACREST provided a guest house to accommodate visiting students and faculty. The students enjoyed simple meals and basic accommodations during their stay. All of the students commented on how hospitable the villagers were in making them feel welcome. 
Transportation was another major difference the students noticed. Seeing 4 or 5 people on a motorbike and overloaded vehicles was very common. The student team got to experience this firsthand during a side trip to Njong village, about 60 kilometers away, to deliver donated books and supplies to local schools. The students made the trip in a van packed with 22 people and supplies, which certainly stuck out as a difference between Cameroon and the United States. In addition, dirt roads are common outside of the cities and major highways. On the way to Bangang Village, the van transporting the team to the village got stuck on a muddy uphill road, forcing the team to hike the final 4 kilometers to the village in the dark and rain, while dragging their luggage along with them. The ACREST staff took the heavier luggage to the guest house at the village on motorized utility carts, but it was still quite an ordeal. Again, this gave the students a greater appreciation of the conveniences modern engineering has brought to the industrialized world.

The lifestyle in Bangang Village was also quite eye opening to the students. The pace of life is much slower and the students were impressed with the "no worries" attitude of the people. Despite the poverty though, Cameroon is a country with an abundance of natural beauty. In addition to working on their projects, the students had the opportunity to do some sightseeing as well. One of their favorite spots was a waterfall, which was about a 3 kilometer hike from the ACREST guest house. See Figure 8. In addition to its natural beauty, the river feeding the waterfall is the source for a hydroelectric generator which not only provides the ACREST facilities with power, but also supplies about 15 families in Bangang Village with low cost electricity.

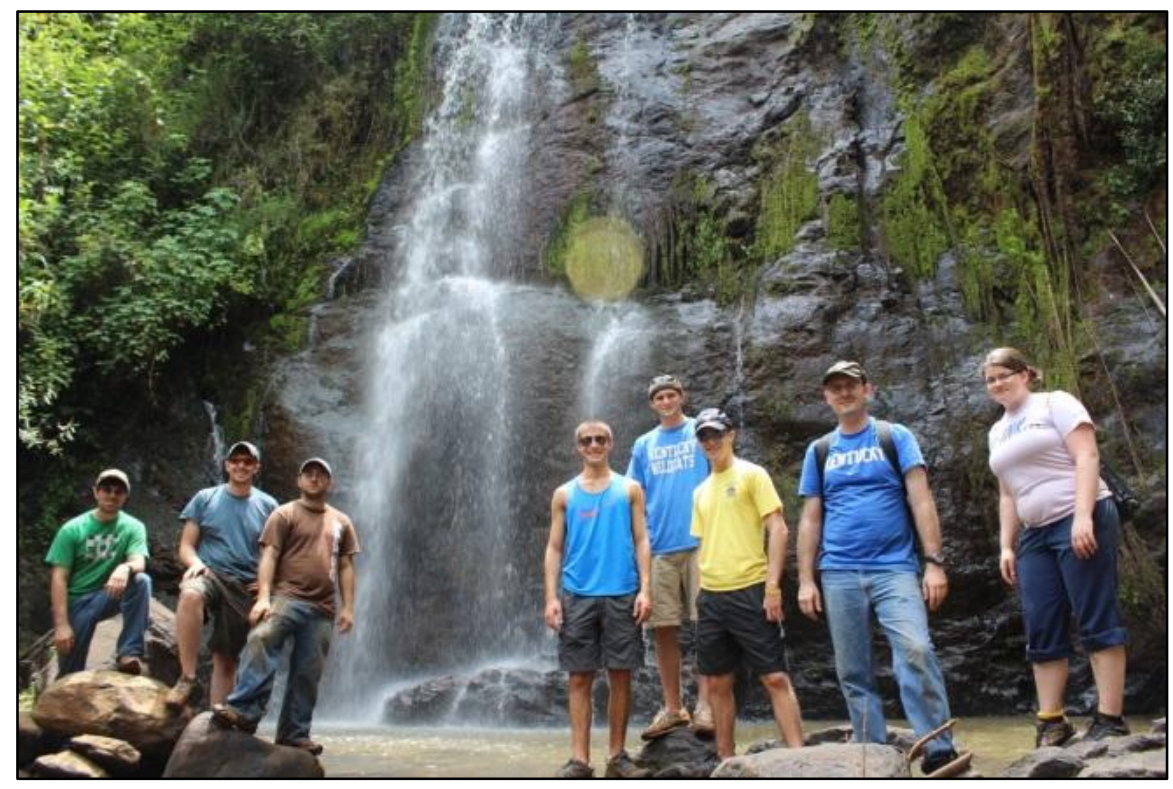

FIGURE 8

UKATS STUDENTS ENJOYING THE WATERFALLS NEAR BANGANG VILLAGE, CAMEROON

Building and using the processor in Cameroon provided the UKATS research students with additional challenges. After seeing the materials that had been selected for use in building the processor at the ACREST facility, the design team came up with a fabrication plan that was easier to carry out than the previous one, although the design itself was smaller. These design 
modifications would never have been conceived without traveling to Cameroon and experiencing the challenges of fabrication firsthand.

This service based design project puts a great deal of emphasis on the concept of renewable energy, something that's also very important in ACREST's work. The ACREST facility makes use of hydro power, but in the dry season, hydro is insufficient to run all of their equipment, and so they use a diesel generator to provide the required energy. In order to produce more energy during the dry season at ACREST, the UKATS team hopes to further develop the biodiesel project in the future, allowing them to make full use of renewable energy sources all year round. Seeing the direct impacts their projects had on the village was inspiring for the student team.

\section{Lessons in Sustainability from Cameroon}

Although the author and undergraduate team has been involved in sustainability for years, the team found that there is certainly more to learn about it. When those of us in the field talk about a sustainable process, we mean a process that is economically viable, environmentally benign and socially responsible. For those in industrialized countries, the focus has been on making the case for renewable energy based on advances in reducing cost and on the potential environmental benefits. It is more difficult however to make the case for societal benefits. In industrialized countries, for all practical purposes, people have access to as much energy as they care to pay for. When people plug in their electronic devices or fill their fuel tanks, they get the same benefit whether the energy source is sustainable or not. It's difficult to make the case that people's lives will be improved with renewable energy - at least in the short term. Powering our houses with coal is just as easy as with wind power or nuclear energy. In a place like Cameroon, the social benefits of renewable energy are much clearer. Because renewable energy can be deployed on a small scale, it fits a need that can't easily be met with traditional energy sources. In the developing world, renewable energy can directly improve lives where running power lines or building fuel pipelines just isn't possible. This has been the most important lesson learned in Cameroon, and certainly changed the perspective of the participating students and faculty.

Additionally, the UKATS group learned an important lesson in undertaking sustainable design projects for the developing world. The initial approach was to examine each component of the industrial process and try to figure out a way to recreate it without the benefit of electricity or computer controls. This was entirely the wrong approach. Although it has become a cliché, the right approach was to think outside the box. What was required instead was to decompose the problem down to its fundamental components. In other words, the right approach was to set aside solutions that are appropriate in the industrialized world, and instead try to solve the problems from scratch within the constraints of the developing world. Once the group realized this, truly creative solutions were possible. This was the second important lesson from our collaboration with ACREST.

\section{CONClusions AND PATH ForWARd}

Although the initial visit to the ACREST facility was successful - the student team managed to build their prototypes and produce both biodiesel and biochar using only local resources - there is still much work to be done. In the long term, palm oil is not a sustainable feedstock for producing biodiesel. Palm oil is a staple in the local diet and as such cannot be used as a long term solution to the fuel needs in rural Cameroon or other countries in tropical regions. Castor 
oil shows promise as an alternative - it grows well in the region and is generally not consumed as a food source; however, it can be toxic and could pose a health risk to unprotected workers who harvest or process the seeds. The UKATS research group will continue to work with ACREST to develop a truly sustainable technology for producing biodiesel and the raw materials

\section{ACKNOWLEDGEMENT}

The authors wish to acknowledge the assistance of the African Center for Renewable Energy and Sustainable Technology, the University of Kentucky Office for International Affairs and the UKATS student team members, Max Croft, William Croft, Mitchell Peeler, Christopher Sterrie, Zac Watson and Christina Willett, who participated in the project.

\section{REFERENCES}

\footnotetext{
${ }^{1}$ Massachusetts Institute for Technology (2008), http://d-lab.mit.edu/sites/default/files/CornSheller_BG.pdf.

${ }^{2}$ Lumkes, John, “Global Design - Global Impact”, Resource - Engineering and Technology for a Developing World, Vol. 19, No. 3, pp. $4-6,2012$.

${ }^{3}$ Whipple, W and J. Seay. "Bridging the Gap Between Science and Engineering for High School Students through an Innovative Biofuel Research Project", Proceedings of the 2011 American Society of Engineering Education Annual Conference, CD Volume, 2011.
}

${ }^{4}$ Brundtland, G., Chairman, United Nations World Commission on Environment and Development. Our Common Future. Toronto, Ontario: Oxford University Press, 1987.

${ }^{5}$ National Academy of Engineering (NAE). The Engineer of 2020: Visions of Engineering in the New Century, The National Academies Press, Washington, DC., 2004.

${ }^{6}$ Lacks, Daniel, Mohan Sankaran and Clever Ketlogetswe. "Experiential Learning and Global Perspective in an Engineering Course”, Journal of Chemical Engineering Education, Vol. 46, No. 2, pp 110 - 117, 2012.

${ }^{7}$ National Science Foundation (NSF). "Science and Engineering Indicators" http://www.nsf.gov/statistics/ seind06/ c8/c8.cfm?opt=2\&selected=yes\&action=map\& colname=814, 2006.

${ }^{8}$ CPE. “Kentucky Post Secondary Education Profile 2008 - 2010”, Kentucky Council on Post Secondary Education, [identifying URL hidden], 2010.

${ }^{9}$ Alovert, Maria. The Biodiesel Homebrew Guide, version 9, 2004.

${ }^{10}$ Lehmann, Johannes. “A Handful of Carbon”, Nature, No. 447, pp. 143-144, 2007.

11 Yoshimura, Hisashi, Hisako Washio, Sadao Yoshida, Takao Seino, Mitsuho Otaka, Kazunori Matsubara and Matsutoshi Matsubara . "Promoting effect of wood vinegar compounds on fruit-body formation of Pleurotus ostreatus", Mycoscience, Vol. 36, No. 2, pp. 173 - 177, 1995.

${ }^{12}$ U.S. Central Intellegence Agency (CIA). The World Factbook. On-line resource. https://www.cia.gov/library/publications/the-world-factbook/geos/cm.html, 2012. 